Goldschmidt 2021 Abstract

https://doi.org/10.7185/gold2021.6076

\section{Disruption of $\mathrm{Zn}$ homeostasis in breast tumour patients reflected in $\mathbf{Z n}$ concentrations and stable isotope compositions of tumours, healthy tissue, and urine}

\author{
KAJ SULLIVAN ${ }^{1,2}$, KATHRIN SCHILLING $^{3}$, DR. \\ REBEKAH ET MOORE ${ }^{2}$, MILES CAPPER ${ }^{2}$, DANIEL \\ LAYTON-MATTHEWS ${ }^{1}$, MATTHEW LEYBOURNE ${ }^{4}$, \\ CHARLES COOMBES $^{2}$, FIONA LARNER ${ }^{5,6}$ AND MARK \\ REHKÄMPER ${ }^{2}$ \\ ${ }^{1}$ Queen's University \\ ${ }^{2}$ Imperial College London \\ ${ }^{3}$ Columbia University \\ ${ }^{4}$ Queen's University \\ ${ }^{5}$ University of Oxford \\ ${ }^{6}$ Rutherford Appleton Laboratory \\ Presenting Author: kajvsullivan@gmail.com
}

To study Zn dyshomeostasis associated with breast cancer, $\mathrm{Zn}$ concentrations and isotopic compositions $\left(\delta^{66} \mathrm{Zn}\right)$ were determined in benign and malignant tumours, healthy tissue from reduction mammoplasty, and histologically normal tissue adjacent to benign (NAT(BT)) and malignant tumours (NAT(MT)) (Sullivan et al., under review). Zinc concentrations and $\delta^{66} \mathrm{Zn}$ were also determined in urine in an effort to provide a non-invasive approach for tracing malignancy-induced $\mathrm{Zn}$ dyshomeostasis and evaluate whether $\mathrm{Zn}$ isotope signatures present are specific to breast cancer and/or observed in the benign condition (Schilling et al., under review). Benign and malignant tumours contain elevated levels of $\mathrm{Zn}$ compared to healthy tissue ( $p=0.0001$ and $p=0.0002$, respectively) and NAT(MT) $(p<0.0001)$. In contrast, $\mathrm{Zn}$ concentrations in NAT(BT) are significantly elevated compared to HT ( $p=$ $0.0022)$ and NAT(MT) $(p=0.0006)$ and may be associated with a specific immune response to benign tumours [1]. Interestingly, the mean $\delta^{66} \mathrm{Zn}$ of both benign and malignant tumours is lower than in healthy tissue ( $p=0.04$ and $p=0.02$, respectively) and $\operatorname{NAT}(\mathrm{BT})(p=0.03$ and $p=0.01$, respectively), indicating a resultant ${ }^{66} \mathrm{Zn}$-rich reservoir may exist in patients with breast tumours. Previous work has shown that the $\mathrm{Zn}$ isotope signature in serum from breast cancer patients is similar to healthy controls [2]. Consistent with this, there is negligible difference in the $\delta^{66} \mathrm{Zn}$ in urine from breast cancer patients and healthy controls $(p$ $=0.32$ ). However, paradoxically, the disruption of $\mathrm{Zn}$ homeostasis in patients with benign tumours is reflected in slightly higher urinary $\mathrm{Zn}$ concentrations $(p=0.12)$ and significantly lower $\delta^{66} \mathrm{Zn}(p=0.03)$ relative to healthy controls. Opposite to what was expected given the increased $\mathrm{Zn}$ concentrations and preferential uptake of ${ }^{64} \mathrm{Zn}$ in benign tumours compared to NAT and healthy tissue, this represents an interesting basis for discussion. With the caveat that the analysis of additional samples is required, urine $\delta^{66} \mathrm{Zn}$ may have the potential to non-invasively indicate whether a breast lump is benign or malignant.

[1] Comtesse, Zippel, Walle et al. (2005), PNAS 102, 9601-6.

[2] Larner, Woodley, Shousha et al. (2015), Metallomics 7, $112-7$. 